\title{
VOLATILIZAÇÃO DA AMÔNIA DA UREIA ESTABILIZADA COM NBPT NA ADUBAÇÃO EM COBERTURA DA Urochloa ruziziensis
}

\author{
João Eudes Santana Lima ${ }^{1}$, Adriano Stephan Nascente ${ }^{2}$, Pedro Marques Silveira ${ }^{2}$, Wilson Mozena Leandro ${ }^{1}$ \\ ${ }^{1}$ Universidade Federal de Goiás - UFG. ${ }^{2}$ Embrapa Arroz e Feijão, Santo Antônio de Goiás, Go. Email: \\ adriano.nascente@embrapa.br
}

\section{RESUMO}

A ureia é o principal adubo nitrogenado utilizado em pastagens. Nesse fertilizante, uma das principais perdas de nitrogênio $(N)$ está relacionada com a volatilização da amônia. $O$ uso de produtos que proporcionam redução das perdas de $\mathrm{N}$ da ureia pode contribuir para aumentar a eficiência de uso desse nutriente em pastagens. Assim, objetivou-se determinar o efeito de fontes e doses de $\mathrm{N}$ aplicado parcelado em cobertura na Urochloa ruziziensis, nas perdas de $\mathrm{N}$ pela volatilização de amônia $\left(\mathrm{N}-\mathrm{NH}_{3}\right)$. O experimento foi conduzido em Santo Antônio de Goiás, GO, em Latossolo Vermelho Distrófico. Utilizou o delineamento experimental de blocos ao acaso, com quatro repetições em arranjo fatorial $2 \times 5 \times 5$. Os tratamentos foram compostos pelas fontes de $\mathrm{N}$ : ureia comum e ureia com inibidor de urease, doses de $\mathrm{N}: 0,50,100$, 200 e $300 \mathrm{~kg} \mathrm{ha}^{-1}$ (parceladas em 5 apliçções) e cinco períodos de crescimento da forrageira: 14/11 a 13/12 (10 período), 14/12 a 12/01 (2 período), 13/01 a 11/02 (3 período), 24/03 a 22/04 (4 período), e 10/07 a 08/08 (5 período). O uso de ureia com inibidor de urease proporcionou reduções nas perdas de amônia por volatilização em relação à ureia comum. $\mathrm{O}$ aumento das doses de $\mathrm{N}$ proporcionou aumento da volatilização de $\mathrm{N}-\mathrm{NH}_{3}$. Ocorreram maiores perdas de $\mathrm{N}$ pela volatilização da amônia nos períodos mais secos do ano.

Palavras-chave: cerrado; forragem; adubação nitrogenada; perdas de nitrogênio; inibidor de urease.

\section{AMMONIA VOLATILIZATION FROM STABILIZED UREA WITH NBPT OF THE TOPDRESSING FERTILIZATION IN Urochloa ruziziensis}

\begin{abstract}
Urea is the major nitrogen fertilizer used in pastures. In this fertilizer, one of the main nitrogen $(\mathrm{N})$ losses is related to ammonia volatilization. The use of products that provide reduced losses of $\mathrm{N}$ from urea can help to increase the use efficiency of this nutrient in pastures. This study aimed to determine the effect of nitrogen sources and doses split applied at topdressing in Urochloa ruziziensis in the $\mathrm{N}$ losses by ammonia $\mathrm{N}-\mathrm{NH}_{3}$ volatilization. The experiment was conducted in Santo Antônio de Goiás, GO, in a in a Brazilian Oxisol. It was used the randomized blocks experimental design, with four replications, in a factorial arrangement $2 \times 5 \times 5$. Treatments were composed by $\mathrm{N}$ sources: common urea and urea with urease inhibitor, $\mathrm{N}$ rates: $0,50,100,200$ and $300 \mathrm{~kg} \mathrm{ha}^{-1}$ (split in 5 applications) and five forage growth period:

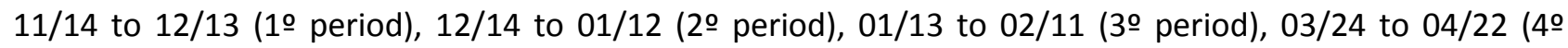
period) and $07 / 10$ to $08 / 08$ (5o period). The use of urea with urease inhibitor provided reductions in ammonia loss by volatilization in comparison to the common urea. Increasing $\mathrm{N}$ rates led to increased $\mathrm{N}$ $\mathrm{NH}_{3}$ volatilization. In drier periods of the year it was found greater losses of $\mathrm{N}$ by ammonia volatilization.
\end{abstract}

Keywords: cerrado; forage; nitrogen fertilization; nitrogen losses; urease inhibitor.

\section{INTRODUÇÃO}

Nas pastagens do cerrado, $80 \%$ das áreas apresentam algum estágio de degradação (BORGHI et al., 2013). A degradação de pastagens pode ser definida como sendo a perda de vigor, produtividade e capacidade natural de cobertura do solo, diminuindo a produção e qualidade de pastagens, necessárias para suportar animais e 
superar os efeitos indesejáveis de insetos, doenças e plantas daninhas (KLUTHCOUSKI et al., 2003). Para aumentar a produtividade das pastagens, a melhoria da fertilidade do solo é fundamental, sendo que a adubação nitrogenada exerce função crucial na produção de fitomassa das gramíneas (COSTA et al., 2008).

$\mathrm{O}$ nitrogênio é um dos nutrientes que mais apresentam transformações nos solos, estando sujeito a grandes perdas (CANTARELLA, 2007; NASCENTE et al., 2011; MORO et al., 2014). A ureia é o principal adubo nitrogenado utilizado no Brasil (IPNI, 2014). Esse fertilizante apresenta uma série de vantagens tais como: menor preço por unidade de $\mathrm{N}$; alta concentração de $\mathrm{N}$, que reduz o custo de transporte e da aplicação; alta solubilidade; menor corrosividade; compatibilidade com grande número de outros fertilizantes e defensivos; e alta taxa de absorção foliar (FAGERIA, 2014). No entanto, a principal desvantagem da ureia é a possibilidade de altas perdas de $\mathrm{N}$ por volatilização de amônia $\left(\mathrm{N}-\mathrm{NH}_{3}\right)$ (KOELLIKER; KISSEL, 1988; CANTARELLA, 2007). Estima-se que de 10 a $25 \%$ do $\mathrm{N}$ aplicado via ureia a lanço, em pastagem, sejam perdidos por volatilização (PRIMAVESI et al., 2005). Em condições favoráveis a volatilização, como elevada temperatura, ausência de precipitação imediatamente depois da adubação e altas taxas de evaporação de água do solo, as perdas podem atingir até $80 \%$ do $\mathrm{N}$ aplicado via ureia (MARTHA JUNIOR et al., 2009).

Várias modificações têm sido feitas em fertilizantes contendo ureia a fim de reduzir as perdas por volatilização de $\mathrm{N}-\mathrm{NH}_{3}$ e aumentar a sua eficiência de uso. Essas modificações incluem a adição de produtos acidificantes (MIKKELSEN; BOCK, 1988; BREMNER; DOUGLAS, 1971) e a produção de fertilizantes com solubilidade controlada por meio de resinas ou polímeros ou mesmo com a cobertura de enxofre elementar (GOULD et al., 1986; MORO et al., 2014). Entretanto, esses produtos comerciais devido ao elevado preço, são utilizados em nichos de mercado de culturas de alto valor agregado e não competem com os adubos convencionais (CIVARDI et al., 2011). Nesse sentido, a identificação de produtos comerciais que proporcionam redução nas perdas de $\mathrm{N}$ pode viabilizar o seu uso e possibilitar também redução da contaminação ambiental.

Os inibidores de urease mais efetivos com forte ação inibidora e com baixa concentração é o NBPT (Tiofosfato de Nitrogênio
- $\mathrm{n}$ - butiltriamida). Depois de aplicado ao solo junto a ureia, inibe a urease por período de 3 a 14 dias, dependendo das condições de umidade e temperatura do solo. Testes realizados no Brasil indicam período de inibição de 3 a 7 dias e após este período, o NBPT perde gradativamente seu efeito inibidor (CANTARELLA et al., 2003, 2008). Zaman et al. (2008) testaram NBPT e dose de 150 $\mathrm{kg} \mathrm{ha}^{-1}$ de $\mathrm{N}$ em pastagem consorciada de azevém e trevo branco, e verificaram que a utilização de ureia + NBPT reduziu em $45 \%$ as perdas por volatilização em relação à ureia sem NBPT. Santos et al. (2013) relataram que no capim marandu a utilização da ureia com o NBPT proporcionou aumentou em $915 \mathrm{~kg} \mathrm{ha}^{-1}$ na produção de biomassa da forrageira, quando comparada à aplicação apenas da ureia.

O trabalho teve como hipótese que o uso de ureia com inibidor de urease irá proporcionar redução nas perdas de $\mathrm{N}-\mathrm{NH}_{3}$ por volatilização. Sendo assim, objetivou-se com este trabalho determinar o efeito de fontes e doses de nitrogênio aplicado parcelado em cobertura na Urochloa ruziziensis nas perdas de nitrogênio pela volatilização de amônia.

\section{MATERIAL E MÉTODOS}

O experimento foi desenvolvido em área experimental da Fazenda Capivara pertencente à Embrapa Arroz e Feijão, localizada no município de Santo Antônio de Goiás, GO $\left(16^{\circ}\right.$ $27^{\prime}$ de latitude, 49o $17^{\prime}$ de longitude e $823 \mathrm{~m}$ de altitude). $O$ clima é classificado como Aw, tropical de savana, mesotérmico, segundo a classificação de Koppen (1936). Durante a condução do experimento a precipitação pluvial $e$ as temperaturas máximas e mínimas do ar foram registradas (Figura 1). O solo do estudo foi classificado como Latossolo Vermelho Distrófico, de textura argilosa, com relevo suavemente ondulado (EMBRAPA, 2013). Antes da instalação do experimento, realizou-se a caracterização química e granulométrica do solo na profundidade de 0 a $20 \mathrm{~cm}$, com os seguintes resultados: $\mathrm{pH}\left(\mathrm{H}_{2} \mathrm{O}\right)=5,90 ; \mathrm{Al}\left(\mathrm{cmol}_{\mathrm{c}} \mathrm{dm}^{-3}\right)=1,7$; $\mathrm{H}+\mathrm{Al}\left(\mathrm{cmol}_{\mathrm{c}} \mathrm{dm}^{-3}\right)=3,6 ; \mathrm{Ca}\left(\mathrm{cmol}_{\mathrm{c}} \mathrm{dm}^{-3}\right)=1,77$; $\mathrm{Mg}\left(\mathrm{cmol}_{\mathrm{c}} \mathrm{dm}^{-3}\right)=0,72 ; \mathrm{P}$ Mehlich-1 $\left(\mathrm{mg} \mathrm{dm}^{-3}\right)=$ 16,80; $\mathrm{K}\left(\mathrm{cmol}_{\mathrm{c}} \mathrm{dm}^{-3}\right)=0,48 ; \mathrm{CTC}\left(\mathrm{cmol}_{\mathrm{c}} \mathrm{dm}^{-3}\right)=$ 6,55; V\% = 45\%; Cu $\left(\mathrm{mg} \mathrm{dm}^{-3}\right)=2,40 ; \mathrm{Zn}\left(\mathrm{mg} \mathrm{dm}^{-3}\right.$ $\left.{ }^{3}\right)=6,23 ; \mathrm{Fe}\left(\mathrm{mg} \mathrm{dm}^{-3}\right)=73,30 ; \mathrm{Mn}\left(\mathrm{mg} \mathrm{dm}^{-3}\right)=$ 14; matéria orgânica $\left(\mathrm{g} \mathrm{kg}^{-1}\right)=22,0$. A análise granulométrica foi feita pelo método da pipeta e apresentou os seguintes resultados analíticos: areia $=319,47 \mathrm{~g} \mathrm{~kg}^{-1}$; silte $=93,33 \mathrm{~g} \mathrm{~kg}^{-1}$ e argila $=$ 
$587,20 \mathrm{~g} \mathrm{~kg}^{-1}$. A metodologia utilizada foi a proposta no manual de métodos da Embrapa

Figura 1. Temperatura máxima, mínima e precipitação pluvial mensal durante a condução do experimento.

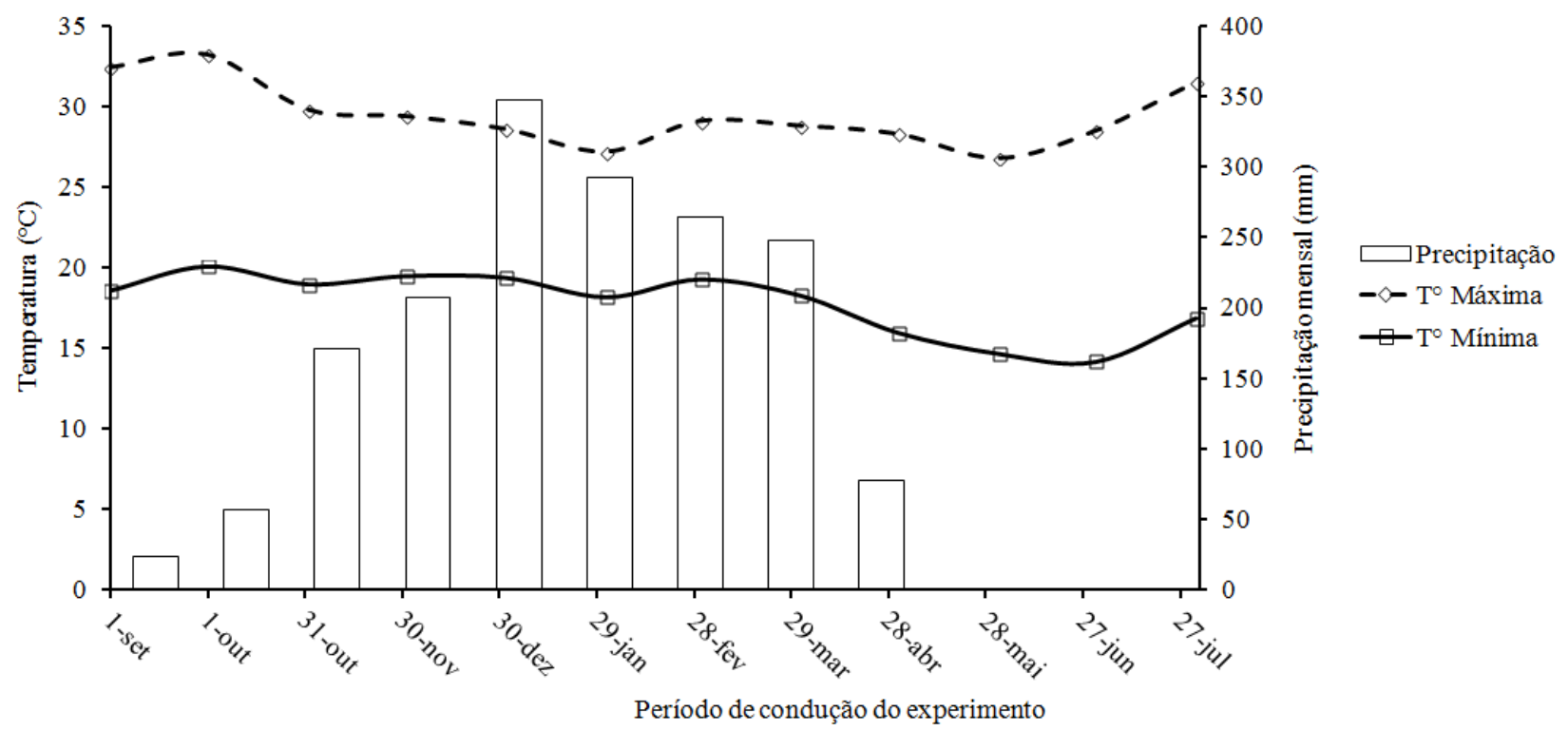

$\mathrm{Na}$ área experimental foi implantada a pastagem de Urochloa ruziziensis por meio do consórcio com o milho no ano anterior. Assim, tratava-se de pastagem de um ano quando se iniciou o experimento. 0 período experimental no campo compreendeu de outubro/2007 a agosto/2008. Assim, em novembro de 2006 foi feita a semeadura do milho híbrido BR 3123 no espaçamento de $0,90 \mathrm{~m}$. As sementes da forrageira Urocholoa ruziziensis foram misturadas no adubo de semeadura do milho e semeadas no espaçamento de $0,45 \mathrm{~m}$. A adubação de base foi de $400 \mathrm{~kg} \mathrm{ha}^{-1}$ utilizando-se a fórmula $\left(\mathrm{N}-\mathrm{P}_{2} \mathrm{O}_{5}{ }^{-}\right.$ $\left.\mathrm{K}_{2} \mathrm{O}\right)$ 5-30-15 e foi feita adubação nitrogenada, em cobertura, com $60 \mathrm{~kg} \mathrm{ha}^{-1}$ de $\mathrm{N}$ como ureia. Utilizou-se $15 \mathrm{~kg} \mathrm{ha}^{-1}$ de sementes da forrageira com valor cultural de $50 \%$.

Foi utilizado o delineamento experimental de blocos casualizados, com quatro repetições em esquema fatorial $2 \times 5 \times 5$. As parcelas tinham a dimensão de $32 \mathrm{~m}^{2}(4 \times 8 \mathrm{~m})$, sendo considerado como área útil $21 \mathrm{~m}^{2}(3 \times 7$ $\mathrm{m})$, em que se descartou $0,5 \mathrm{~m}$ de cada lado da parcela. Os tratamentos foram compostos por duas fontes de ureia: a convencional e a ureia com inibidor de urease, cinco doses de N: $0,10 \mathrm{~kg}$ $\mathrm{ha}^{-1}$ de N por aplicação (tratamento 50), $20 \mathrm{~kg} \mathrm{ha}{ }^{-}$ ${ }^{1}$ de $\mathrm{N}$ por aplicação (tratamento 100), $40 \mathrm{~kg} \mathrm{ha}^{-1}$ de $\mathrm{N}$ por aplicação (tratamento 200) e $60 \mathrm{~kg} \mathrm{ha}^{-1}$ de $\mathrm{N}$ por aplicação (tratamento 300 ), aplicadas em cobertura, parceladamente, logo após cada período de crescimento e cinco períodos de crescimento, de 30 dias cada: 14/11 a 13/12 (1을 período), 14/12 a 12/01 (2 período), 13/01 a 11/02 (3ㅇ período), 24/03 a 22/04 (4o período) e 10/07 a 08/08 (5o período). No dia 12/11, antes do primeiro crescimento, foi feito um corte de uniformização das parcelas a $15 \mathrm{~cm}$ de altura e removido todo material vegetal cortado. Esse procedimento foi repetido em todos os demais períodos, logo após a amostragem da parcela, realizando-se um corte total em toda a extensão da parcela e removendo o material vegetal. Em relação à ureia com inibidor de urease, utilizou-se a ureia estabilizada com NBPT (trifosfato de nitrogênio - $\mathrm{n}$ - Butiltriaminda).

Para avaliação da volatilização de amônia em kg ha ${ }^{-1}$ foi utilizado sistema de coleta por câmara estática, confeccionada a partir de frascos plásticos transparente tipo PET de dois litros, sem a base, com diâmetro de $10 \mathrm{~cm}$, abrangendo $0,0078 \mathrm{~m}^{2}$ de área, seguindo metodologia proposta por Araújo et al. (2009). No interior do frasco, foi suspenso com auxílio de arame inoxidável e encapado, uma espuma de $2,5 \mathrm{~cm}$ de largura e $25 \mathrm{~cm}$ de comprimento umedecida com solução de ácido sulfúrico $(1,5$ mol $\mathrm{dm}^{-3}$ ) e glicerina (4\%) (ARAÚJO et al., 2009). A garrafa PET foi cortada na base, e usou esta base de forma invertida na extremidade superior, suspensa por arame formando um chapéu para evitar a entrada de água da chuva (Figura 2). 
Figura 2. Câmara coletora de amônia (N-NH$)$. Santo Antônio de Goiás. Foto: Tatiely Gomes Bernardes.

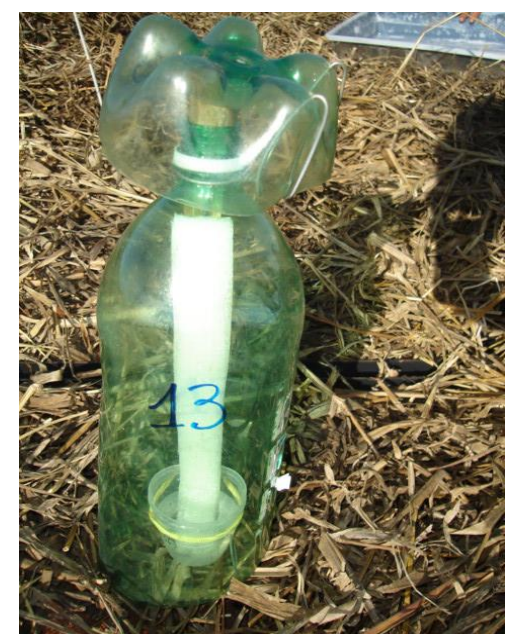

Para a medição da volatilização de amônia, adicionou $30 \mathrm{~mL}$ de solução de ácido sulfúrico $\left(1,5 \mathrm{~mol} \mathrm{dm}^{-3}\right)$ com $4 \%$ de glicerina no frasco plástico de $80 \mathrm{~mL}$, que fica dentro da câmara. Posteriormente a espuma de polietileno foi embebida na solução de ácido sulfúrico e glicerina e deixada dentro do frasco. No interior da garrafa, suspendeu-se a espuma e com auxílio de arame inoxidável e elástico, fixou-se um frasco de $80 \mathrm{~mL}$.

A coleta das espumas para determinação da volatilização da amônia foi feita no primeiro período a cada sete dias. Entretanto, verificou-se que a espuma coletora da amônia volatilizada estava saturada, o que poderia ter causado a não captação de todo o nitrogênio volatilizado. Diante disso, do segundo período em diante a coleta das espumas passou a ser feita três dias após a adubação e a troca das espumas foi feita sucessivamente no mesmo intervalo de tempo.

No laboratório, à espuma juntamente com a solução ácida no frasco de $80 \mathrm{~mL}$, adicionou-se $40 \mathrm{~mL}$ de água destilada, totalizando $70 \mathrm{~mL}$ de solução. Os frascos foram tampados e agitados por 30 minutos. Uma alíquota de $5 \mathrm{~mL}$ foi transferida para tubo de ensaio, a qual foi levada para destilação e titulação com ácido sulfúrico. $O$ teor de $\mathrm{N}$ nos frascos aos $3,6,9,15$, $18,21,24,27$ e 30 dias após a adubação foi determinada pelo método de Kjeldahl (MALAVOLTA et al., 1997). Com os valores de cada coleta, fez-se a somatória e obteve-se a volatilização total de amônia em cada período.
Foi feita a análise de variância e análise de regressão $(p \leq 0,05$ para $\circ$ fator quantitativo dose de N). Com os dados de perda de $\mathrm{N}$ pela volatilização da amônia em cada período de 30 dias fez-se a estimativa das perdas acumuladas no período total em cada dose de $\mathrm{N}$, ou seja, com os dados das perdas de $\mathrm{N}$ em cada dose, multiplicou-se por cinco (meses com umidade) e obteve-se a quantidade de $\mathrm{N}$ perdida nos cinco meses; com os dados fez-se a análise de regressão $(p \leq 0,05)$. Em todas as análises estatísticas utilizou-se o pacote estatístico SAS (SAS, 1999).

\section{RESULTADOS E DISCUSSÃO}

Constatou-se efeito das interações período de crescimento $x$ doses de nitrogênio $e$ fontes de nitrogênio $x$ doses de nitrogênio (Tabela 1). Na primeira avaliação ocorrida no período de $14 / 11$ a 13/12 (1 período) verificouse os menores valores de perdas de amônia por volatilização (Figura 3 ). Esse menor valor pode ter sido reflexo dessa primeira coleta ter sido feita a cada sete dias, como explicado anteriormente.

Por outro lado, a avaliação da produção de massa seca da parte aérea, densidade de perfilhos, teor de nitrogênio total na folha e teor relativo de clorofila não foram afetados pelas fontes de $\mathrm{N}$, como relatado por Lima et al. (2016), em avaliações realizadas no mesmo experimento. Entretanto, as doses de nitrogênio proporcionaram incrementos lineares em todas as avaliações e com maiores valores no período chuvoso. 
Tabela 1. Volatilização total de amônia em 30 dias, em solo com plantas de Urochloa ruziziensis em razão de fontes e doses de nitrogênio e períodos de crescimento da Urochloa ruziziensis.

\begin{tabular}{|c|c|}
\hline $\begin{array}{ll}\text { Fatores } \\
\end{array}$ & Volatilização de amônia $\left(\mathrm{kg} \mathrm{ha}^{-1}\right)$ \\
\hline \multicolumn{2}{|l|}{ Fontes de nitrogênio } \\
\hline Ureia comum & 25,04 \\
\hline Ureia estabilizada & 16,47 \\
\hline \multicolumn{2}{|l|}{ Doses de nitrogênio $\left(\mathrm{kg} \mathrm{ha}^{-1}\right)$} \\
\hline 0 & 6,92 \\
\hline 50 & 10,35 \\
\hline 100 & 18,49 \\
\hline 200 & 25,77 \\
\hline 300 & 42,27 \\
\hline \multicolumn{2}{|l|}{ Períodos de crescimento } \\
\hline 14/11 a 13/12 (1ㅇ período) & 5,70 \\
\hline 14/12 a 12/01 (2o período) & 22,03 \\
\hline 13/01 a 11/02 (3ำ período) & 13,85 \\
\hline 24/03 a 22/04 (4ㅇ período) & 31,78 \\
\hline 10/07 a 08/08 (5o período) & 30,44 \\
\hline Fatores & ANOVA - Probabilidade do teste $\mathrm{F}$ \\
\hline Fontes de $\mathrm{N}$ (FN) & $<0,001$ \\
\hline Doses de $\mathrm{N}$ (DN) & $<0,001$ \\
\hline Período de crescimento (PC) & $<0,001$ \\
\hline $\mathrm{FN} \times \mathrm{DN}$ & $<0,001$ \\
\hline$D N \times P C$ & $<0,001$ \\
\hline $\mathrm{FN} \times \mathrm{PC}$ & 0,4563 \\
\hline$F N \times D N \times P C$ & 0,7868 \\
\hline
\end{tabular}

Figura 3. Volatilização total de amônia em 30 dias com Urochloa ruziziensis em razão do período de crescimento da forrageira e doses de nitrogênio. ${ }^{* *}$ significativo para $p<0,01$, ns=não significativo.

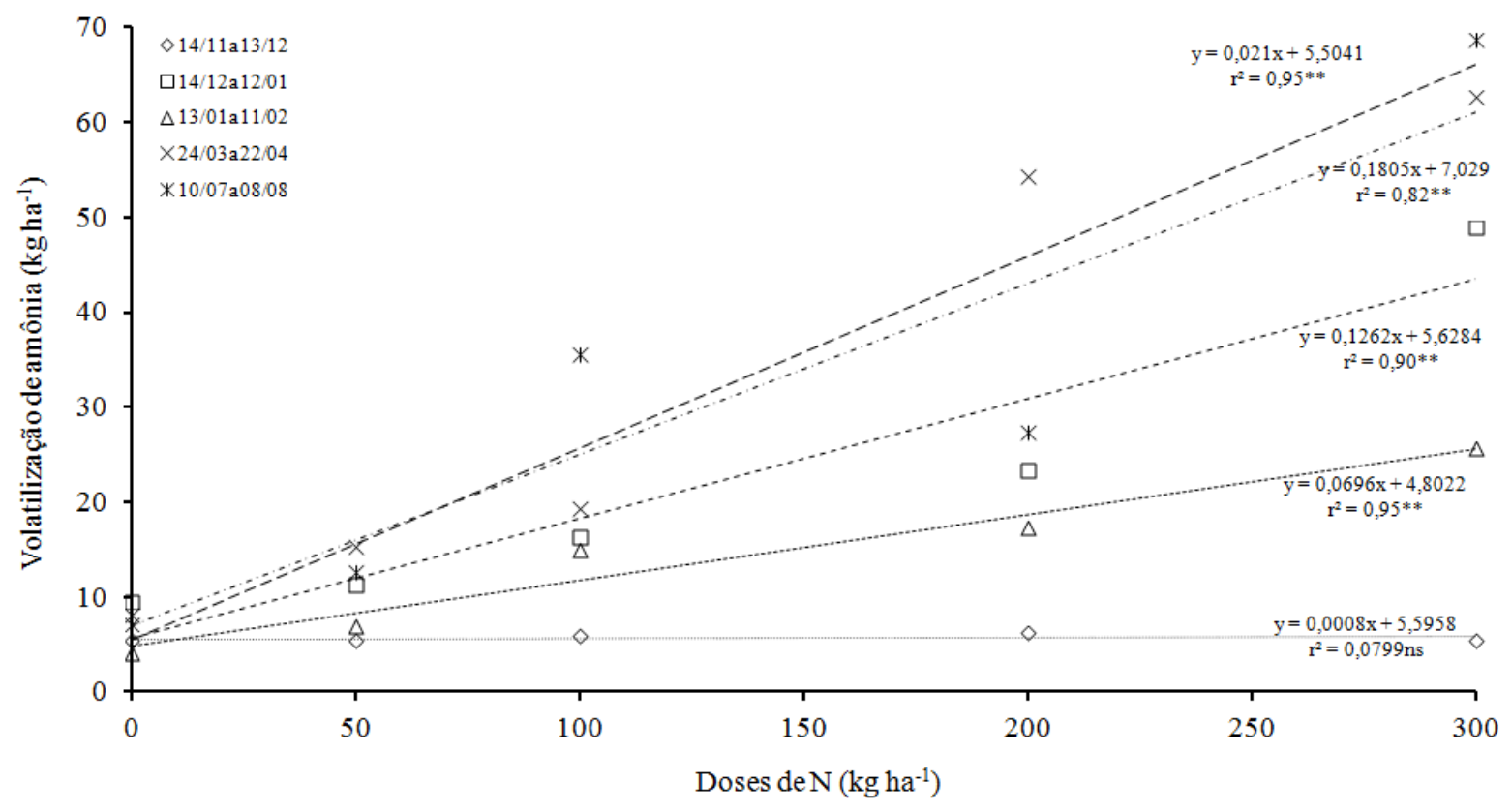

As perdas de amônia no período de $14 / 12$ a 12/01 (2 período) foram superiores ao do período de 13/01 a 11/02, 3o período (Tabela 1, Figura 3). Esse fato ocorreu principalmente devido as menores precipitações no 2 으 período em relação ao 3o período. As perdas de nitrogênio dependem principalmente da precipitação pluvial e da temperatura (FAGERIA, 2014). Quanto maior a temperatura e menor a precipitação, maiores serão as perdas de 
nitrogênio pela volatilização. Adicionalmente, a umidade do solo na ocasião da adubação interfere diretamente na hidrólise da ureia, e consequentemente, nas perdas por volatilização da amônia. Ou seja, o umedecimento do solo, imediatamente após a aplicação da ureia, é mais importante do que a condição de umidade do solo no momento da apliçção, principalmente quando a ureia é aplicada na superfície do solo e sem incorporação (LARA CABEZAS et al., 1997). Ros et al. (2006) acrescentam que a água aplicada após a adubação com ureia ou a ocorrência de precipitação, pode diminuir a volatilização da amônia se for suficiente para diluir a concentração de oxidrilas $\left(\mathrm{OH}^{-}\right)$, ao redor dos grânulos de ureia, que foram produzidos na reação de hidrólise, além de proporcionar a incorporação da ureia no solo. Com base nos dados climáticos (Figura 1), observa-se que as temperaturas máximas foram superiores no segundo período $\left(29,4^{\circ} \mathrm{C}\right)$ em relação ao terceiro $\left(28,6{ }^{\circ} \mathrm{C}\right)$. Além disso, no terceiro período ocorreram mais chuvas $(347,8 \mathrm{~mm})$ do que no segundo período $(207,30 \mathrm{~mm})$, o que pode ter contribuído para reduzir a volatilização de amônia (TRIVELIN et al., 2002). Nos períodos de 24/03 a 22/04 (4o período) e 10/07 a 08/08 (5o período) houve redução na precipitação pluvial (248 e $0 \mathrm{~mm}$, para os dois períodos respectivamente), proporcionando, devido a menor precipitação, maior perda de nitrogênio pela volatilização de amônia no 5ㅇ período.
A volatilização amoniacal acumulada foi crescente com o aumento da adubação nitrogenada (Figura 4). Martha Júnior et al. (2009) estudaram perdas de nitrogênio por volatilização da amônia na adubação com ureia e também verificaram que a volatilização acumulada foi maior nas doses mais elevadas da adubação nitrogenada. Da mesma forma, Barth et al. (2006) observaram incremento proporcionalmente maior das perdas de $\mathrm{N}$ com o aumento da dose das fontes amídicas, sendo que nas doses de 100 e $150 \mathrm{~kg} \mathrm{ha}^{-1}$ de $\mathrm{N}$ as perdas foram maiores do que o dobro ou triplo do que na dose menor de $50 \mathrm{~kg} \mathrm{ha}^{-1}$, como observado no presente experimento. Assim, considerando a maior dose nitrogenada do experimento, $300 \mathrm{~kg}$ ha ano ${ }^{-1}$ de nitrogênio, a volatilização de amônia proporcionou perdas de mais de $200 \mathrm{~kg}$ ha ano ${ }^{-1}$ de nitrogênio. Entretanto, vale ressaltar que as maiores doses de $\mathrm{N}$ também proporcionaram em porcentagem maior retenção do nutriente no solo. Dessa forma, constata-se que no tratamento 50 perdeu-se $51,8 \mathrm{~kg} \mathrm{ha}^{-1}$ de $\mathrm{N}$, no tratamento 100 , perdeu-se $92,5 \mathrm{~kg} \mathrm{ha}^{-1}$ de $\mathrm{N}$, no tratamento 200 , perdeu-se $128,9 \mathrm{~kg} \mathrm{ha}^{-1}$ de $\mathrm{N}$, e no tratamento $300,211,4 \mathrm{~kg} \mathrm{ha}^{-1}$ de $\mathrm{N}$. A dose 50 proporcionou maiores perdas de $\mathrm{N}$ do que a quantidade aplicada, sendo, portanto $\mathrm{N}$ do solo. Da mesma forma, na dose 0 , ocorreram perdas de cerca de $30 \mathrm{~kg} \mathrm{ha}^{-1}$ de $\mathrm{N}$.

Figura 4. Volatilização acumulada de amônia no solo no período de $14 / 11$ a 08/08 com Urochloa ruziziensis em razão de doses de nitrogênio. ${ }^{* *}$ significativo para $p<0,01$

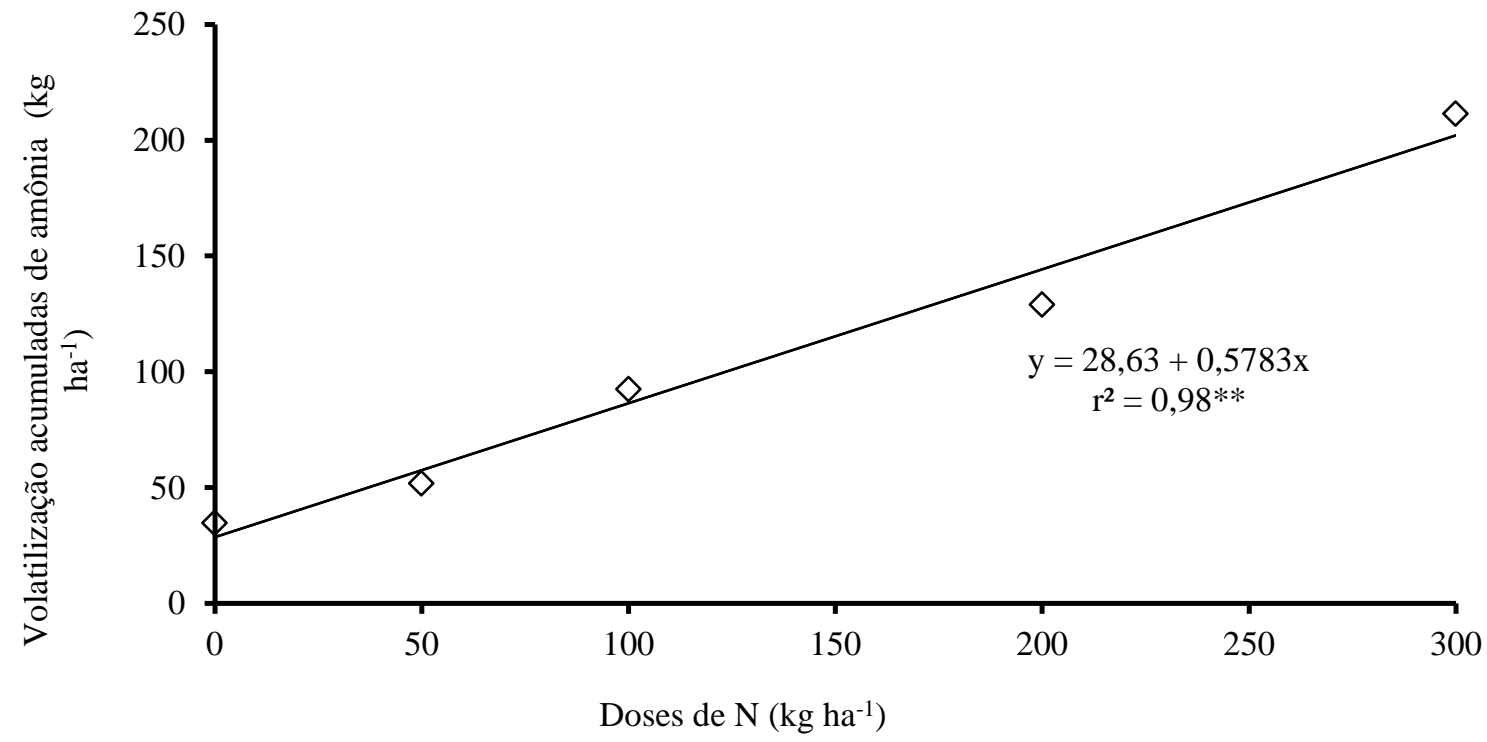


$\mathrm{Na}$ prática, quando os ciclos de pastejos são de 30 dias, considerando um período chuvoso de 180 dias, teremos aproximadamente seis ciclos de pastejo e seis adubações na forrageira (KLUTHCOUSKI et al. 2003), podendo assim ter perdas consideráveis de N (CANTARELLA, 2007). Nesse sentido, verifica-se que o uso da ureia com inibidor de urease (NBPT) foi eficiente na redução na volatilização da amônia (Figura 5). Dessa forma, constatou-se que a ureia comum apresentou maior perda de $\mathrm{N}$ por volatilização $\left(25,04 \mathrm{~kg} \mathrm{ha}^{-1}\right)$ em relação à ureia com inibidor de urease $(16,48$ $\mathrm{kg} \mathrm{ha}^{-1}$ ) (Tabela 1). Ou seja, a ureia estabilizada foi $52 \%$ menos volátil que a ureia comum. Cantarella et al. (2008) e Pereira et al. (2009) também constataram que ureia com inibidor de urease reduziu à metade as perdas de $\mathrm{N}-\mathrm{NH}_{3}$ por volatilização. Entretanto, Weereden et al. (2016) verificaram que a aplicação de ureia com inibidor de urease em pastagem teve pouco ou nenhum efeito nas perdas de N. Nesse sentido, Almeida (2016) relata que com base nos resultados de pesquisas anteriores, o uso de fertilizantes de liberação controlada e com inibidores, embora não em todas as situações, contribuem para redução das perdas de $\mathrm{N}$ nos agroecossistemas.

Com base nos resultados obtidos no presente experimento, verifica-se que o uso da ureia com inibidor de urease é eficiente para reduzir as perdas de $\mathrm{N}$ por volatilização de amônia e com isso poderia contribuir de forma efetiva para o aumento na eficiência de uso desse adubo nitrogenado. No entanto, conforme já relatado por Lima et al. (2016), na avaliação da produção de massa seca da forrageria, não se observou efeito da fonte de adubo nitrogenado nessa variável, mas verificou-se que o uso de doses de adubo nitrogenado foi eficiente para proporcionar incrementos na produção e qualidade da forrageira Urochloa ruziziensis. Entretanto, esse aumento na produção também proporciona incrementos nas perdas de $\mathrm{N}$ por volatilização da amônia. Adicionalmente, constatou-se que o uso da ureia com inibidor de urease nao proporcionou melhoria da qualidade da forrageria (LIMA et al., 2016).

Figura 5. Volatilização total de amônia em 30 dias, em solos com Urochloa ruziziensis em razão da fonte nitrogenada e de doses de nitrogênio. ${ }^{* *}$ significativo para $p<0,01$

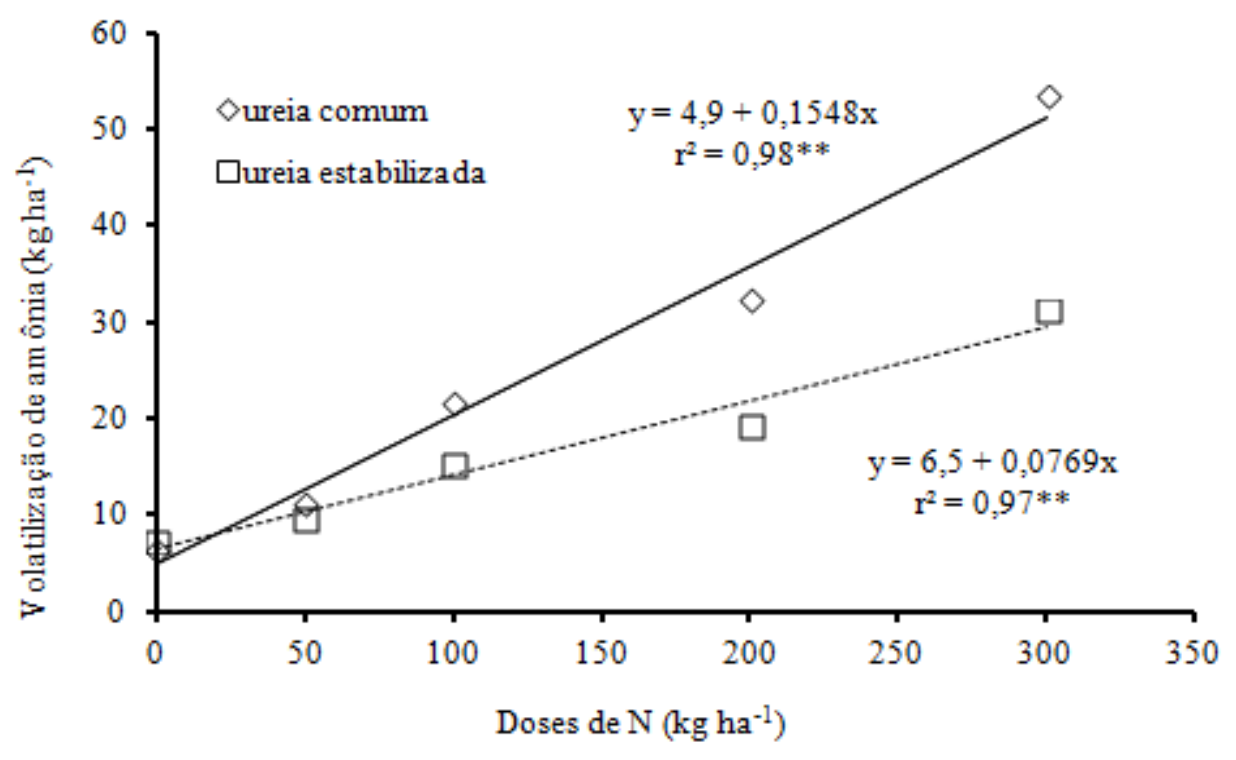

\section{CONCLUSÕES}

O uso de ureia com inibidor de urease proporcionou reduções nas perdas de nitrogênio por volatilização de amônia em relação à ureia comum;

O aumento das doses de nitrogênio proporcionou aumento da volatilização de amônia;
Ocorreram maiores perdas de nitrogênio pela volatilização da amônia nos períodos mais secos do ano.

\section{AGRADECIMENTOS}

Ao Conselho Nacional de Desenvolvimento Científico e Tecnológico (CNPq) pela bolsa de produtividade em pesquisa ao segundo e quarto autor. 


\section{REFERÊNCIAS}

ALMEIDA, R.E.M. Fertilizantes de eficiência aumentada: uso de ureia de liberação controlada ou com inibidores em sistemas agrícolas sustentáveis. Palmas: Embrapa Pesca e Aquicultura, 2016.

ARAÚJO, E.S.; MARSOLA, T.; MIYAZAWA, M.; SOARES, L.H.B.; URQUIAGA, S.; BODDEY, R.M.; ALVES, B.J.R. Calibração de câmara semi-aberta estática para quantificação de amônia volatilizada do solo. Pesquisa Agropecuária Brasileira, v.44, n.7, p.769-776, 2009. https://doi.org/10.1590/S0100$\underline{\text { 204X2009000700018 }}$

BARTH, G.; VITTI, G. C.; CANTARELLA, H.; VITTI, A. C. Volatilização de $\mathrm{N}-\mathrm{NH}_{3}$ quanto as fontes e doses de nitrogênio aplicadas sobre a palhada de cana de açúcar. In: Fertbio 2006, Bonito. Anais... Viçosa: Sociedade Brasileira de Ciência do Solo, 2006.

BORGHI, E.; CRUSCIOL, C.A.C.; NASCENTE, A.S.; SOUSA, V.V.; MARTINS, P.O.; MATEUS, G.P.; COSTA, C. Sorghum grain yield, forage biomass production and revenue as affected by intercropping time. European Journal of Agronomy, v.51, p.130-139, 2013. https://doi.org/10.1016/i.eja.2013.08.006

BREMNER, J. M.; DOUGLAS, L. A. Decomposition of urea phosphate in soils. Soil Science Society of American Journal, v.35, n.4, p.575-578, 1971.

CANTARELLA, H.; TRIVELIN, P.C.O.; CONTIN, T.L.M.; DIAS, F.L.F.; ROSSETO, R.; MARCELINO, R.; COIMBRA, R.B.; QUAGGIO, J.A. Ammonia volatilization from urease inhibitor-treated urea applied to sugarcane trash blankets. Scientia Agricola, v.65, n.4, p.397-401, 2008. https://doi.org/10.1590/S0103-

$\underline{90162008000400011}$

CANTARELLA, H.; MATTOS, D.; QUAGGIO, J.A.; RIGOLIN, A.T. Fruit yield of Valencia sweet orange fertilized with different $\mathrm{N}$ sources and the loss of applied N. Nutrient Cycling in Agroecosystems, v.67, n.3, p.215-223, 2003. https://doi.org/10.1023/B:FRES.0000003600.204 $\underline{99.76}$

CANTARELLA, H. Nitrogênio. In: NOVAIS, R.F.; ALVAREZ V., V.H.; BARROS, N.F.; FONTES, R.L.F.;
CANTARUTTI, R.B.; NEVES, J.C.L. Fertilidade do solo. Viçosa: SBCS, 2007. p.375-470.

CIVARDI, E.A.; SILVEIRA NETO, A.N.; RAGAGNIN, W.A.; GODOY, E.R.; BROD, E. Slow-release urea applied to surface and regular urea incorporated to soil on maize yield. Pesquisa Agropecuária Tropical, v.41, n.1, p.52-59, 2011. https://doi.org/10.5216/pat.v41i1.8146

CLAESSEN, M.E.C. Manual de métodos de análise de solo. 2. ed. Rio de Janeiro: Embrapa, 1997.

COSTA, K.A.P.P.; FAQUIN, V.; OLIVEIRA, I.P.; RODRIGUES, C.; SEVERIANO, E.C. Doses e fontes de nitrogênio em pastagem de capim-marandu. I - Alterações nas características químicas do solo. Revista Brasileira de Ciência do Solo, v.32, n.4, p.1591-1600, 2008.

https://doi.org/10.1590/S0100$\underline{06832008000400023}$

ROS, C.O.D.; AITA, C.; GIACOMINI, S.J. Volatilização de amônia com aplicação de uréia na superfície do solo, no sistema plantio direto. Ciência Rural, v.35, n.4, p.799-805, 2005. https://doi.org/10.1590/S0103-

$\underline{84782005000400008}$

EMBRAPA. Sistema brasileiro de classificação de solos. 3. ed. Brasília: EMBRAPA, 2013.

FAGERIA, N.K. Nitrogen management in crop production. Boca Raton: CRC, 2014. https://doi.org/10.1201/b17101

GOULD, W.D.; HAGEDORN, C. MCCREADY, R.G.L. Urea transformation and fertilizer efficiency in soil. Advances in Agronomy, v.40, p.209-238, $1986 . \quad$ https://doi.org/10.1016/S00652113(08)60283-7

IPNI. Fertilizantes. 2014. Disponível em: http://brasil.ipni.net/article/brs-3132\#aparente. Acesso em: 05 dez. 2015.

KLUTHCOUSKI, J.; STONE, L.F.; AIDAR, H. Integração lavoura-pecuária. Santo Antônio de Goiás: Embrapa Arroz e Feijão, 2003.

KOELLIKER, J.K.; KISSEL, D.E. Chemical equilibria affecting ammonia volatilization. In: BOCK, B.R.; KISSEL, D. E. Ammonia volatilization from urea 
fertilizers. Alabama: National Fertilizer Development Center, 1988. p.37-52.

KOPPEN, W. Handbuck der Klimatologie. Berlin: Borntraeger Science Publishers, 1936.

LARA CABEZAS, W.A.R.; KORNDORFER, G.H.; MOTTA, S.A. Volatilização de $\mathrm{NNH}_{3}$ na cultura de milho: II. Avaliação de fontes sólidas e fluídas em sistema de plantio direto e convencional. Revista Brasileira de Ciência do Solo, v.21, p.489-496, 1997. https://doi.org/10.1590/S0100$\underline{06831997000300019}$

LIMA, J.E.S.; NASCENTE, A.S.; LEANDRO, W.M.; SILVEIRA, P.M. Urochloa ruziziensis responses to sources and doses of urea. Revista Brasileira de Engenharia Agrícola e Ambiental, v.20, n.5, p.401407, 2016. https://doi.org/10.1590/18071929/agriambi.v20n5p401-407

MALAVOLTA, E.; VITTI, G. C., OLIVEIRA, S. A. Avaliação do estado nutricional das plantas: princípios e aplicações. 2. ed. Piracicaba: Potafos, 1997.

MARTHA JUNIOR, G.B.; CORSI, M.; TRIVELIN, P.C.O.; VILELA, L. Recuperação de ${ }^{15} \mathrm{~N}$-ureia no sistema solo-planta de pastagem de capimtanzânia. Revista Brasileira de Ciência do Solo, v.33, n.1, p.95-101, 2009. https://doi.org/10.1590/S0100-

$\underline{06832009000100010}$

MIKKELSEN, R.L.; BOCK, B.R. Ammonia volatilization from urea phosphate fertilizers. In: BOCK, B.R.; KISSEL, D.E. Ammonia volatilization from urea fertilizers. Alabama: National Fertilizer Development Center, 1988. p.175-189.

MORO, E.; CRUSCIOL, C.A.C.; NASCENTE, A.S.; CANTARELLA, H. Nitrification inhibition in tropical soil under no tillage system. Revista de Ciências Agrárias, v.57, n.2, p.199-206, 2014. https://doi.org/10.4322/rca.2014.015

NASCENTE, A.S.; KLUTHCOUSKI, J.; RABELO, R.R.; OLIVEIRA, P.; COBUCCI, T.; CRUSCIOL, C.A.C. Produtividade do arroz de terras altas em função do manejo do solo e da época de aplicação de nitrogênio. Pesquisa Agropecuária Tropical, v.41, n.1, p.60-65, 2011.
PEREIRA, H.S.; LEÃO, A.F.; VERGINASSI, A.; CARNEIRO, M.A.C. Ammonia volatilization of urea in the out-of-season corn. Revista Brasileira de Ciência do Solo, v.33, n.6, p.1685-1694, 2009. https://doi.org/10.1590/S0100-

$\underline{06832009000600017}$

PRIMAVESI, A.C.; PRIMAVESI, O.; CORRÊA, L.A.; CANTARELLA, H.; SILVA, A.G. Absorção de cátions e ânions pelo capim-coastcross adubado com uréia e nitrato de amônio. Pesquisa Agropecuária Brasileira, v.40, n.3, p.247-253, 2005. https://doi.org/10.1590/S0100$\underline{204 \times 2005000300008}$

SANTOS, K. M. Emissão de óxido nitroso e volatilização de amônia em pastagem de capimmarandu. 2013. 62 f. Dissertação (Mestrado Produção Animal Sustentável) - Instituto de Zootecnia, Nova Odessa.

SAS. Procedure guide for personal computers. Version 5. Cary: Sas Institute, 1999.

TRIVELIN, P.C.O.; OLIVEIRA, M.W.; VITTI, A.C.; GAVA, G.J.C.; BENDASSOLLI, J.A. Perdas do nitrogênio da ureia no sistema solo-planta em dois ciclos de cana-de-açúcar. Pesquisa Agropecuária Brasileira, v.37, n.2, p.193-201, $2002 . \quad$ https://doi.org/10.1590/S0100$\underline{204 \times 2002000200011}$

WEEREDEN, T.J.V.D.; LUO, J.; DI, H.J.; PODOLYAN, A.; PHILLIPS, R.L.; SAGGAR, S.; KLEIN C.A.M.; COX,N.; ETTEMA, P.; RYS, G. Nitrous oxide emissions from urea fertiliser and effluent with and without inhibitors applied to pasture. Agriculture, Ecosystems and Environment, v. 219, n.1, p.58-70, 2016. https://doi.org/10.1016/i.agee.2015.12.006

ZAMAN, M.; NGUYEN, M. L.; BLENNERHASSETT, J. D.; QUIN, B. F. Reducing $\mathrm{NH}_{3}, \mathrm{~N}_{2} \mathrm{O}$ and $\mathrm{NO}_{3}-\mathrm{N}$ losses from a pasture soil with urease or nitrification inhibitors and elemental S-amended nitrogenous fertilizers. Biology and Fertility of Soils, v.44, n.5, p.693-705, 2008. https://doi.org/10.1007/s00374-007-0252-4

Recebido para publicação em 26/10/2017

Revisado em 29/01/2018

Aceito em 27/03/2018 